\title{
The Study of the Relationship between Organizational Culture and Organizational Agility in Agricultural Bank
}

\author{
Zeynab FAHAMI $^{1, *}$, Hojjat Allah Moradi PORDANJANI ${ }^{2}$, Mohammad Taghi MAHMOUDI ${ }^{2}$, \\ Ferdos MONTAZER-AL-ZOHOUR ${ }^{2}$ \\ ${ }^{1}$ Master Student in Educational Management, Islamic Azad University, Shahrekord, Iran \\ ${ }^{2}$ Faculty Member Of Azad University, Shahrekord, Iran \\ *Corresponding author: Email: Zeynabfahami65@gmail.com
}

\begin{abstract}
This study has been done on the relationship between organizational culture and organizational agility in Agricultural Bank of Chaharmahal and Bakhtiari Province; it is an applied and descriptive-field research also the study is correlational. The statistical population was all employees in Agricultural Bank of Chaharmahal and Bakhtiari Province and 260 subjects were selected as the statistical population by using Morgan table. After analyzing data, it was clear that the increase in each indicator of organizational culture leads to increase agility in Agricultural Bank of Chaharmahal and Bakhtiari Province.
\end{abstract}

Keywords: Engaging in work, Consistency, Adaptability, Mission and organizational agility

\section{Introduction}

Since today's complex world has been named as the continuity era also with the rapid growth and evolution of technical knowledge and technology and expanding consumer market, the opportunity to use past experiences and solutions has been taken from man. Other past experiences and solutions are not suitable for current issues and the future of organizations. Another way and new solutions should be taken to be able to provide goods and services with that quality the customer wants. Finding creative ways to respond to today's changing environment and achieving to the success of organizations require the use of new methods and a new approach to the organization [1]. In recent decades, the success of organizations has been depended on their ability and capacity to identify customers' needs and to provide fast and inexpensive services in accordance with their needs. Today, "agility" as the dominant paradigm of business in the third millennium and as the best option to survive organizations has been considered by service and manufacturing organizations. Regarding this matter, some efforts have been made to achieve the proper level of agility in these organizations; in the current economy that achieving to profitability requires to consider customers' changes and needs in other words it is the implementation of agility approach in the organization, banks as the institutions that play an important role in the economy and prosperity of a country should take useful and effective steps to check the customers' needs, changes of environment and the actions of competitors (2). Providing suitable, reliable, fast, 
inexpensive and adequate services will ensure the survival and continuity of financial institutions activities in both parts in order to meet the expectations and demands of customers and to take their consent and loyalty (3). This cannot be achieved unless the bank creates agility and the culture of agility in the structure of the organization and among the employees in this close competition. Because organizational culture has affected all organizational aspects, it empowers organizations based on common beliefs and values; also agility, organizational structure and systems of agility, targeting, developing and implementing policies and strategies to achieve agility have an effect on the attitude of individual behavior, motivation and job satisfaction and labors' efficiency level. Thus, by examining the relationship between culture, the most effective element in the organization, and considering agility as a new paradigm in achieving success and aligning with the changes, the main objective of this study is providing some guidelines for those researchers and organizations that intend to investigate agility.

\subsection{Organizational Culture}

Like people, organizations have some characters named as the culture of that organization [4]. The existence of cultural identity, beliefs, values, and common behavior norms of organization members lead to integrated efforts, internal commitment to the organization and a clear understanding of the philosophy and purpose of actions and finally the success of organization. In other words the impressive success of organizations in strong intangible factors of organizational culture is hidden in the employees' values and beliefs. Culture plays different roles in an organization, firstly culture determines the boundaries of the organization, secondly, it injects a sense of identity in the members of the organization, and thirdly culture makes a commitment in people that it is more important than personal interests (5). The definition of organizational culture is not possible in a specified format i.e. there is no general accepted definition (6) (7). Organizational culture is considered as a powerful force that determines how to act and how to operate. He believes that organizational culture refers to basic values, beliefs and principles that serve to management system as a solid foundation. In addition, all values and beliefs and the management system strengthen the primary principles. These principles and values are continuous because they contain specific meanings for the members of the organization. He believes that the messages that come from the organizational culture are closely linked to the organization's strategy and have great impact on the people who work there. Denison states that culture is not easily seen or touched; but the organization members are well known with it and the law of culture is stronger than any other law. In many organizations, this is the most important message of culture (8).

\subsection{Denison Organizational Culture Model}

Denison has used a model to show the culture of the organization. This model highlights four key traits of the culture of an organization named as involvement, adaptability, consistency, and mission. These four traits are expressed in terms of management activities. Management activities include determined functions related to four traits of organizational culture also they are derived from beliefs, values and assumptions dominating on the organization and being strengthened by them. These management activities are measured by using 12 indices that form the model (9). 


\subsection{Involvement}

Organizational cultures characterized as "highly involved" strongly encourage employee involvement in different activities of organization and create a sense of ownership and responsibility in them; ownership grows a greater commitment to the organization and an increasing capacity or autonomy. In this kind of culture, the employees rely on informal, voluntary, and implied control systems, rather than formal, explicit, bureaucratic control systems. The organization empowers its employees and improves their capabilities at all levels of the organization. As a result, all organizational members get skills and the ability to make decisions in their activity fields also receiving input from organizational members increases the quality of the decisions and improves their implementations (10).

The indices of the Involvement Trait are:
A: empowerment
B: Team Orientation
C: Capability Development

\subsection{Consistency (Stability and Integrity)}

Consistency is defined as values and systems that are the basis of a strong culture. Due to the existence of a consistent and coordinated culture, the integrated organizations are highly intended to efficiency. In these organizations, members' behavior is rooted in a set of central values and the organizational members have a high skill to achieve agreement even in unfamiliar situations. Consistency enables individuals to better react in a predictable way to an unpredictable environment by emphasizing value-based principles.

The indices of the Consistency Trait are:
A: Coordination and Integration
B: Agreement
C: Core Values

\subsection{Adaptability}

Adaptability means paying attention to the requirements of the business environment in the activities of associable organizations that hold a system of norms and beliefs that increase the organization's capacity to receive, interpret, and translate signals from its environment into internal behavioral changes that enhances its chances for survival, growth, and development. Three aspects of adaptability impact an organization's effectiveness: first is the ability to perceive and respond to the external environment; Successful organizations are very focused on their customers and competitors. Second is the ability to respond to internal customers, regardless of level, department or function. Third is the capacity to restructure and re-institutionalize a set of behaviors and processes that allow the organization to adapt. If an organization doesn't have this ability to implement adaptive response, it cannot be effective.

The indices of the Adaptability trait are:
A: Creating Change 


\section{B: Customer Focus \\ C: Organizational Learning}

\subsection{Mission}

Mission includes definition and determination of long-term directions for the organization. A mission provides purpose and meaning by defining a social role and external goals for the organization. A clear sense of mission allows the individuals to shape current behavior of the organization by envisioning a desired future state. If organization's mission is internalized and the organization is identified by it, it contributes to both short and long-term commitment to the organization. Success is more likely achieved when individuals and organizations are goal directed.

The indices of the Mission Trait are:
A: Strategic Direction and Intent
B: Goals and Objectives
C: Vision

\subsection{Organizational agility}

At the beginning of the $21^{\text {st }}$ century, the world was faced with significant changes in all aspects especially dramatic changes in communication channels, breaking geographical and organizational boundaries and technological innovations, increasing demand and rising customers' expectations and breaking macro markets into smaller and more limited markets that these changes consider the survival of the organizations subject to a major review of their strategic priorities and vision (12). Considering newly emergence of organizational agility paradigm, different definitions have been proposed by the authors, some of which are mentioned here. The ability to act in a competitive environment resulting from continuous changes and rapid reaction to market changes and creating value for products and services based on customer satisfaction (13). In operational terms, agility is a combination of several companies, each with their own skills and competencies that have joined operational cooperation. It enables cooperative companies (with the common profession) to adapt and respond to changes according to customer needs (14). A system with capabilities and efficiencies that leads to the survival and development of firms in a competitive environment; lack of certainty about the system that quickly change is the key feature of this environment and it takes place through product models or changes between product lines (flexibility) and in an ideal state it is an immediate response to customer's need (16).

\subsection{The key capabilities of organization agility}

Agile organizations and institutions are concerned about change, uncertainty and predictability in their business environment that they need a number of distinctive capabilities to examine them. These capabilities include four main elements regarded as the bases for maintaining and developing the agility; they are as follow:

1. Responsibility: the ability of realizing the changes and prompt reply to them.

2. Sufficiency: refers to the ability to achieve the organization's goals. 
3. Flexibility: the ability of manufacturing and presenting different processes and achieving to different goals with the same resources and equipments.

4. Speed: the ability of doing the activities at the shortest possible time (17).

\subsection{Statistical Population}

The statistical population included all employees of the Agricultural Bank of Chaharmahal and Bakhtiari province that during conducting the study, 750 employees were working.

\subsection{Methodology}

In terms of purpose and analysis, it is an applied and correlational study because it tries to find the relationship between organizational culture and organizational agility in the Agricultural Bank of Chaharmahal and Bakhtiari Province. Descriptive method was used to collect data and it is one of the field studies due to using real subjects (employees) in real business work.

\section{Research Hypothesis}

The main hypothesis: there is a relationship between the organizational culture and organizational agility of the employees of Agricultural Bank in Chaharmahal and Bakhtiari province.

Hypothesis 1: there is a significant relationship between involvement in the organizational culture and organizational agility in the Agricultural Bank in Chaharmahal and Bakhtiari province.

Hypothesis 2: there is a significant relationship between the consistency (stability and integrity) of organizational culture and organizational agility in the Agricultural Bank in Chaharmahal and Bakhtiari province.

Hypothesis 3: there is a significant relationship between the adaptability of organizational culture and organizational agility in the Agricultural Bank in Chaharmahal and Bakhtiari province.

Hypothesis 4: there is a significant relationship between the mission of the organizational culture and organizational agility of the employees of Agricultural Bank in Chaharmahal and Bakhtiari province.

\subsection{The results of hypotheses}

Table 1: The simple correlation coefficients between organizational culture and organizational agility of the employees of Agricultural Bank in Chaharmahal and Bakhtiari Province

\begin{tabular}{|c|c|c|c|c|}
\hline Predictor variable & $\begin{array}{c}\text { Statistical index } \\
\text { Criterion variable }\end{array}$ & $\begin{array}{c}\text { Correlation coefficient } \\
(\mathrm{r})\end{array}$ & $\begin{array}{c}\text { Significance level } \\
(\mathrm{p})\end{array}$ & $\begin{array}{c}\text { Sample } \\
(\mathrm{n})\end{array}$ \\
\hline Organizational culture & Organizational agility & 0.74 & 0.0001 & 260 \\
\hline
\end{tabular}

The main hypothesis: there is a relationship between the organizational culture and organizational agility of the employees of Agricultural Bank in Chaharmahal and Bakhtiari province. 
As it is clear in Table 2-4 there is a positive significant positive relationship between organizational culture and organizational agility of the employees of Agricultural Bank in Chaharmahal and Bakhtiari province $(\mathrm{p}=0.0001$ and $\mathrm{r}=0.74)$.

Thus the first hypothesis is confirmed. In other words, increasing the organizational culture of the employees of Agricultural Bank leads to increase their organizational agility.

Table 2: The simple correlation coefficients between dimensions of organizational culture and organizational agility of the employees of Agricultural Bank in Chaharmahal and Bakhtiari

Province

\begin{tabular}{|c|c|c|c|c|}
\hline Predictor variable & Statistical index & $\begin{array}{l}\text { Correlation coefficient } \\
\text { (r) }\end{array}$ & $\begin{array}{c}\text { Significance level } \\
\text { (p) }\end{array}$ & $\begin{array}{l}\text { Sample } \\
\text { (n) }\end{array}$ \\
\hline 1. Involvement & \multirow{4}{*}{ Organizational agility } & 0.67 & 0.0001 & \multirow{4}{*}{260} \\
\hline 2. Consistency (Stability and Integrity) & & 0.63 & 0.0001 & \\
\hline 3. Adaptability & & 0.45 & 0.0001 & \\
\hline 4. Mission & & 0.55 & 0.0001 & \\
\hline
\end{tabular}

Hypothesis 1: there is a significant relationship between involvement in the organizational culture and organizational agility in the Agricultural Bank in Chaharmahal and Bakhtiari province.

As Table 2 shows the Pearson correlation coefficient is used to show the relationship between these two variables $(r=0.67)$ that it is significant at the $p<0.0001$ level. So hypothesis 1 is confirmed in this study.

Hypothesis 2: there is a significant relationship between the consistency (stability and integrity) of organizational culture and organizational agility in the Agricultural Bank in Chaharmahal and Bakhtiari province.

As Table 2 shows the Pearson correlation coefficient is used to show the relationship between these two variables $(r=0.63)$ that it is significant at the $\mathrm{p}<0.0001$ level. So hypothesis 1 is confirmed in this study.

Hypothesis 3: there is a significant relationship between the adaptability of organizational culture and organizational agility in the Agricultural Bank in Chaharmahal and Bakhtiari province.

As Table 2 shows the Pearson correlation coefficient is used to show the relationship between these two variables $(r=0.45)$ that it is significant at the $p<0.0001$ level. So hypothesis 1 is confirmed in this study.

Hypothesis 4: there is a significant relationship between the mission of the organizational culture and organizational agility of the employees of Agricultural Bank in Chaharmahal and Bakhtiari province.

As Table 2 shows the Pearson correlation coefficient is used to show the relationship between these two variables $(r=0.55)$ that it is significant at the $p<0.0001$ level. So hypothesis 1 is confirmed in this study.

\section{Conclusion}

Today, the role of organizational agility and its impact in all fields particularly in the financial markets is known for every person. Achieving agility can improve the quantity and quality of 
services, reduce costs of adverse reactions to changes and cause to prevent the waste of resources, as well as it can increase competitiveness, efficiency and productivity, motivation and job satisfaction in employees. According to the results of similar studies and current research, favorable organizational culture can facilitate the path to get agility. In this close competition, Banks must create agility and the culture of agility in the structure of the organization and between employees and they can establish the culture of agility in the organization through choosing an organizational culture proportionate to their organizational structure. By examining inferential statistics and using Pearson correlation test, primary and secondary hypotheses were tested on intended population. All assumptions were confirmed at the confidence level of $p>0.0001$ and it was showed that there is a significant relationship between the independent variable (organizational agility) and dependent variable (organizational agility) in all aspects. Therefore, as this relationship has been positive we can say that by increasing the organizational culture among the employees of Agricultural Bank in Chaharmahal and Bakhtiari Province, organizational agility will be improved too.

\section{REFERENCES}

[1] Kiasi, S., Boroumand, Z. (2009). Examining and assessing cultural entrepreneurial strategies (Cultural and Art Institutions of Country) and providing desirability model, Cultural Management Magazine, Vol 3, No. 6.

[2] Abdi, N., Salavati, A., Ghasemi, Sh. (2010). Examining the impact of new banking technologies on organizational agility, a case study: Melli Bank of Sanandaj, Iran's Fourth National Conference on Management technology.

[3] Fotros, MH., Beigif, T.(2010). A comparative study of the effects of intellectual capital on organizational performance of banking industry in both private and public section, a case study: Banks in Tehran, Journal of Executive Management (Scientific-Research), Vol 10, No. 1, pp.101- 125.

[4] Ghadami, M., Azari, M. (2010). Presenting management model for cultural development with perspective document 1404, Cultural Management Magazine, Vol 4, No. 7.

[5] Ara'abi, S.M. (2007) Principles of organizational behavior, Cultural Research Office.

[6] Sharifzadeh, F., Kazemi, M. (1998). Managing the culture of the organization. Tehran: Ghomes Publication.

[7] Denison, Daniel. R. cho, H. J., Young j. (2000) Diagnosing organizational culture: validating a model and method, working paper, IMD 2000-9, International Institute for Management Development, Lausanne, pp.1-31.

[8] Iranzadeh, S., Mahmoudi, M. (2010). Realizing and assessing the organizational culture according to Denison Model, Forouzesh Publication, Vol 1, Iran.

[9] Denison, Daniel. R \& Fisher, Carolin. (2005) the role of the Board of Director in shaping corporate culture: Reactive compliance or Visionary leadership? Working paper presented at the changing the Game Forum: Reforming American Business June2-4, 2005 Berver Greek, co.

[10] Forbes, David. And Seena, Sara, (2006). "The Value of a Mission Statement in an Association of not for profit Hospitals", International journal of health care quality assurance, Vol. 19. No. 5 . 
[11] Kolia, Martin. (2002). Relationship between organizational culture, organizational climate and organizational effectiveness. PhD Thesis in Organizational Behabiour, Available at www. Proquest.com.

[12] Oosterhout, Maecel.Van; Waarts, Eric; Heck, Eric.Van \& Hillegersberg, Joes.Van (2007). Business Agility: Need, Readiness and Alignment with IT Strategies, Journal of Agile Information Systems.

[13] Qin, Ruwen. Nembhard, David A. (2010). Workforce agility for stochastically diffused conditions A real options perspective. Int. J. Production Economics 125 (2010) 324-334.

[14] McKenzie, Jane \& Aitken, Paul (2012). Development of digital product catalogue for enabling agility in a manufacturing organization, Strategic HR Review, Vol. 11, Issue: 6, pp. 12-31.

[15] Dries, Nicky; Vantilborgh, Tim \& Pepermans, Roland (2012). The role of learning agility and Career variety in the identification and development of high potential, Personnel Review, Vol. 41, Issue. 3, pp. 1-25.

[16] Sharifi, Hossein, Zhang, David (2001). Agile manufacturing: a management and operational framework. Proceedings of the Institution of Mechanical Engineers Part B-Journal of Engineering Manufacture 215 (6), 857-869.

[17] Rajabzadeh, A., Shahaei, B. (2006). Providing assessment model of agility in public organizations and an introduction to the effect of information technology on the agility of the organization, the second International Conference on Information and Communication Technology Management. 